\title{
CRESCIMENTO E MUDANÇAS FÍSICO-QUÍMICAS DURANTE A MATURAÇÃO DE FRUTOS DE MELOEIRO (Cucumis melo var.cantalupensis Naud.) HÍBRIDO TORREON
}

\author{
Growth and physicochemical changes during the ripening of hybrid Torreon muskmelon fruits \\ (Cucumis melo var. cantalupensis Naud.)
}

\author{
Ricardo Fabiano Hettwer Giehl', Evandro Binotto Fagan², Ana Cristina Eisermann³, \\ Auri Brackmann ${ }^{4}$, Sandro Petter Medeiros ${ }^{4}$, Paulo Augusto Manfron ${ }^{4}$
}

\begin{abstract}
RESUMO
Objetivou-se neste trabalho avaliar o crescimento e as mudanças físico-químicos durante a maturação de melões (Cucumis melo var. cantalupensis Naud.), híbrido Torreon. As plantas foram cultivadas no sistema hidropônico NFT ("Nutrient Film Technique"), em Santa Maria, RS, durante o período de janeiro a abril. Diariamente, foram marcadas as flores pistiladas em antese, anotando-se a data desse evento. Foram efetuadas as medidas lineares do diâmetro longitudinal e transversal dos frutos a cada três dias, iniciandose após a antese. A partir dos 25 dias após a antese (DAA), realizou-se, a cada três dias, a colheita de 10 frutos, aleatoriamente. Foram analisados os parâmetros: síntese de etileno, respiração, firmeza da polpa, teor de sólidos solúveis totais, acidez total titulável e coloração da polpa. O aumento no diâmetro longitudinal e transversal dos frutos ocorreu até aproximadamente os 26-29 DAA. A partir desse momento, iniciou-se o processo de maturação dos frutos. Nessa fase, verificou-se intenso incremento na síntese de etileno, com pico aos 37 DAA ( $\left.44 \pm 4,6 \mathrm{~mL} \mathrm{~kg}^{-1} \mathrm{~h}^{-1}\right)$, o que culminou no aumento da respiração e na diminuição da acidez total titulável e da firmeza de polpa. Além disso, a cor da polpa dos frutos tornou-se gradativamente mais vermelha. Os frutos desprenderam da planta aproximadamente aos $37 \mathrm{DAA}$, quando apresentaram uma média de $10,5^{\circ}$ Brix de sólidos solúveis totais.
\end{abstract}

Termos para indexação: Etileno, qualidade de fruto, crescimento.

\begin{abstract}
This research had the aim of evaluating the physicochemical growth and changes during maturation of hybrid Torreon melons (Cucumis melo var. cantalupensis Naud.). Melon plants were cultivated in the NFT (Nutrient Film Technique) hidroponic system from January to April 2004 in Santa Maria, RS, Brazil. Flowers in anthesis were daily tagged and linear measures of longitudinal and transverse diameter were made at a 3-day interval, beginning at anthesis. Starting from 25 days after anthesis (DAA), 10 fruits were randomly harvested each 3 days. These fruits were individually assessed for ethylene synthesis, respiration rate, flesh firmness, soluble solids contents, titratable acidity and flesh colour. Fruits exhibited growth until approximately 26-29 DAA, when ripening process initiated. A large rise in ethylene synthesis was observed, reaching $44 \mu \mathrm{L} \mathrm{kg}^{-1} \mathrm{~h}^{-1}$ at $34 \mathrm{DAA}$, which was accompanied by an increase in respiration and a decrease of total titratable acidity and flesh firmness of fruit. In addition, flesh colour of fruit became redder, as fruit ripened. Fruits slipped from vine at about 37 DAA showing mean values of total soluble solids of $10.5^{\circ}$ Brix.
\end{abstract}

Index terms: Ethylene, fruit quality, growth.

(Recebido em 8 de novembro de 2006 e aprovado em 6 de agosto de 2007)

\section{INTRODUÇÃO}

O cultivo do meloeiro vem alcançando uma considerável expansão, em função de sua boa aceitação pelo mercado consumidor brasileiro e pela crescente demanda do mercado externo. Entretanto, um dos entraves para seu cultivo é a baixa conservação pós-colheita, principalmente nas variedades cantalupensis e reticulatus. Essas variedades são consideradas climatéricas, por apresentarem rápidas mudanças na composição química durante o período de maturação (BOWER et al., 2002). O amadurecimento de frutos é um processo complexo e geneticamente programado, que resulta em alterações na coloração, no aroma, na textura e no "flavor" dos frutos, tornando-os aptos ao consumo (AYUB et al., 1996).

Em melões, assim como em todos os frutos, o estádio de maturação na colheita é de fundamental importância, pois os teores de açúcares não aumentam após a colheita,

\footnotetext{
${ }^{1}$ Engenheiro Agrônomo, Mestre em Agronomia - Departamento de Fitotecnia/DFito - Universidade Federal de Santa Maria/UFSM - Avenida Roraima, Campus UFSM - 97105-900 - Santa Maria, RS - hetgiehl@yahoo.com.br - Bolsista CNPq

2Engenheiro Agrônomo, Doutorando - Departamento de Produção Vegetal - Escola Superior de Agricultura Luiz de Queiroz/ESALQ - Universidade de São Paulo/USP - Avenida Pádua Dias, 11, sala 30 - Cx. P. 9 - 13418-900 - Piracicaba, SP - evbinotto@yahoo.com.br - Bolsista FAPESP

${ }^{3}$ Engenheira Agrônoma - Departamento de Fitotecnia/DFito - Universidade Federal de Santa Maria/UFSM - Avenida Roraima, Campus UFSM - $97105-900$ Santa Maria, RS - anna_eisermann@yahoo.com.br - Bolsista CNPq

${ }^{4}$ Engenheiros Agrônomos, Doutores - Departamento de Fitotecnia/DFito - Universidade Federal de Santa Maria/UFSM - Avenida Roraima, Campus UFSM - 97105-900 - Santa Maria, RS - brackman@ccr.ufsm.br; sandro_fito@smail.ufsm.br; manfronp@smail.ufsm.br
} 
sendo a colheita geralmente determinada através dos teores de sólidos solúveis totais presentes na polpa (HUBBARD et al., 1989; VILLANUEVA et al., 2000). Frutos colhidos imaturos não alcançam os teores desejados de açúcar, que segundo a Frupex (1994) situam-se entre 9 e $12^{\circ}$ Brix. Por outro lado, a colheita em estádios avançados de maturação pode prejudicar a qualidade dos frutos durante o transporte e armazenamento. O amadurecimento de melões reticulados é acompanhado pelo desenvolvimento de uma zona de abscisão na inserção do pedúnculo com o fruto (KENDALL \& NG, 1988). No entanto, frutos colhidos após a formação completa dessa zona de abscisão apresentam uma grande lesão no local da inserção do pedúnculo, sendo esse um importante ponto para a entrada de organismos patogênicos (SEYMOUR \& McGLASSON, 1993).

Em função da importância da determinação do estádio mais adequado para a colheita, torna-se necessária a avaliação do seu padrão de crescimento e de desenvolvimento a partir do florescimento, o que auxilia no estabelecimento de índices de maturidade. Por exemplo, melões 'Honey Dew' são colhidos a partir dos 35-37 dias após a antese (PRATT et al., 1977), pois nesse estádio apresentam teores adequados de sólidos solúveis totais $\left(10^{\circ}\right.$ Brix $)$, além de possuírem a capacidade de amadurecer após a colheita.

Por causa da necessidade de estudos que avaliem o crescimento e as transformações físico-químicas em melões reticulados, avaliou-se o crescimento e as mudanças que ocorrem nos parâmetros físico-químicos de melões (Cucumis melo var. cantalupensis Naud.), híbrido Torreon cultivados no sistema hidropônico NFT ("Nutrient Film Technique").

\section{MATERIAL E MÉTODOS}

O experimento foi conduzido conjuntamente entre o Núcleo de Pesquisa em Ecofisiologia e Hidroponia (NUPECH) e o Núcleo de Pesquisa em Pós-Colheita (NPP), ambos do Departamento de Fitotecnia da Universidade Federal de Santa Maria - RS, no período de janeiro a abril de 2004. As coordenadas geográficas do local são: latitude $29^{\circ} 43^{\prime} \mathrm{S}$, longitude $53^{\circ} 43^{\prime} \mathrm{W}$ e altitude $95 \mathrm{~m}$. O clima, segundo a classificação de W. Köeppen, pertence ao tipo "Cfa" clima subtropical úmido com verões quentes.

Utilizou-se a variedade Cucumis melo var. cantalupensis Naud., híbrido Torreon, cuja semeadura foi realizada no mês de janeiro em placas de espuma fenólica. Após a semeadura, as placas foram colocadas em bancadas de germinação, constituídas por telha de fibra de vidro, recebendo de duas a três irrigações diárias, somente com água. Ao atingirem duas folhas definitivas, as mudas foram transplantadas para o "berçário", que consistiu de perfis de polipropileno com canais de $3,0 \mathrm{~cm}$ de profundidade, espaçados de 7,0 cm, com distância de $10,0 \mathrm{~cm}$ entre as plantas nos canais. A solução utilizada foi a recomendada por Castellane \& Araújo (1995), diluída para 50\% de sua concentração.

As mudas permaneceram no "berçário" até atingirem cinco a seis folhas definitivas, sendo então transplantadas para o leito de cultivo, que foi constituído por tubos de PVC rígido de $100 \mathrm{~mm}$ de diâmetro com 8,0 m de comprimento, dispostos sobre cavaletes de madeira. Utilizou-se o espaçamento de 1,0 m entre plantas de fileiras distintas e de $0,30 \mathrm{~m}$ entre plantas do mesmo canal, totalizando 26 plantas por canal de cultivo em sistema NFT ("Nutrient Film Technique"). A solução nutritiva utilizada foi a recomendada por Castellane \& Araújo (1995) a 100\%. As irrigações, durante o período diurno (6 às 19 horas) foram realizadas durante 15 minutos, com um intervalo de 30 minutos entre irrigações sucessivas. Durante o período noturno realizou-se uma irrigação de 15 minutos a cada 60 minutos. $\mathrm{O}$ controle do $\mathrm{pH}$ foi realizado a cada dois dias, mantendo-o em 6,0 $\pm 0,2$. Nesse mesmo momento, efetuavase a leitura da condutividade elétrica da solução nutritiva, sendo repostos $50 \%$ dos nutrientes quando essa atingia $50 \%$ da concentração inicial. A condução da cultura foi realizada segundo o método descrito por Caron \& Heldwein (2000). O monitoramento da temperatura e umidade relativa do ar foi realizado através de um termo-higrógrafo, instalado no centro da estufa, na altura de 1,5 m. A radiação solar incidente foi medida através de um sensor do tipo piranômetro, acoplado a um "data loger", que coletava e armazenava os valores a cada cinco minutos.

Para a realização do experimento, foram utilizadas 96 plantas. Diariamente, foram marcadas as flores pistiladas em antese, anotando-se a data desse evento. Com auxílio de um paquímetro, foram efetuadas as medidas lineares do diâmetro longitudinal e transversal dos frutos a cada três dias, iniciando-se após a antese. Limitou-se o número de frutos nessas plantas a um por planta.

A partir dos 25 dias após a antese (DAA), realizouse, a cada três dias, a colheita de 10 frutos com mesma idade, aleatoriamente. Esses foram acondicionados numa câmara climatizada até a temperatura da polpa atingir $20^{\circ} \mathrm{C}$. Nesse momento, avaliou-se individualmente a produção de etileno, a respiração, a firmeza da polpa, os teores de sólidos solúveis totais, a acidez total titulável, a cor da polpa e a dimensão do halo verde da polpa. A produção de etileno foi determinada por meio de cromatografia gasosa, sendo os frutos individualmente acondicionados em tambores de PVC, hermeticamente vedados, durante duas 
horas. Amostras de $1 \mathrm{~mL}$ da composição gasosa, presente no interior dos tambores, foram injetadas em um cromatógrafo a gás Varian ${ }^{\circledR}$ (modelo Star 3400CX), equipado com coluna Porapak N80/100 e detector de ionização de chama. As temperaturas da câmara de injeção, da coluna e do detector foram $90^{\circ} \mathrm{C}, 140^{\circ} \mathrm{C}$ e $200^{\circ} \mathrm{C}$, respectivamente. Os valores foram expressos em $\mu \mathrm{L}$ de etileno $\mathrm{kg}^{-1} \mathrm{~h}^{-1}$. A respiração foi obtida com o uso de um analisador de gases Agridatalog ${ }^{\circledR}$, através do qual circulou-se a composição gasosa dos tambores. Os resultados foram expressos em $\mathrm{mL}$ de $\mathrm{CO}_{2} \mathrm{~kg}^{-1} \mathrm{~h}^{-1}$. A firmeza da polpa foi determinada por meio de um penetrômetro manual, com ponteira de $11 \mathrm{~mm}$ de diâmetro. Para essa determinação, os frutos foram seccionados transversalmente na região equatorial. A firmeza foi mensurada em quatro pontos da polpa dos frutos, no sentido pedúnculo-apical, sendo expresso o valor médio de cada fruto em Newton $(\mathrm{N})$. Os teores de sólidos solúveis totais (SST) foram determinados de duas formas: no suco obtido pela centrifugação de toda a polpa e em seis pontos distintos da polpa (basal ou peduncular, mediana e apical tanto próximo à casca quanto à cavidade central), com o uso de um refratômetro manual com compensação da temperatura para $20^{\circ} \mathrm{C}$. Os teores foram expressos em ${ }^{\circ}$ Brix. A acidez total titulável (ATT) foi obtida por meio da titulação, com $\mathrm{NaOH} 0,1 \mathrm{~N}$, de $10 \mathrm{~mL}$ de suco diluídos em $100 \mathrm{~mL}$ de água destilada e deionizada, até atingir $\mathrm{pH} 8,1$. Posteriormente, os resultados foram transformados para $\mathrm{g}$ de ácido cítrico $100 \mathrm{~mL}^{-1}$ de polpa. A cor da polpa foi determinada por um colorímetro marca Minolta ${ }^{\circledR}$ (modelo CR-310) pelo sistema CIE L*a*b*. Os resultados foram expressos, conforme proposto por Mcguire (1992), em ângulo de cor $\left(h^{\circ}\right)$, onde $h^{\circ}=\operatorname{arco}$ tangente $\left(b^{*} / a^{*}\right)$, e em croma $\left(C^{*}\right)$, sendo $C^{*}=\left[\left(a^{* 2}+b^{* 2}\right)^{1 / 2}\right]$. Além disso, determinou-se a proporção do halo verde da polpa, mensurando-se a extensão da polpa com coloração verde e o diâmetro transversal total da polpa.

Os resultados, de cada variável, foram expressos através da média e os desvios-padrões obtidos nas avaliações realizadas aos 25, 28, 31, 34 e 37 dias após a antese. A síntese de etileno e a respiração também foram determinados aos 40 DAA. Os teores de sólidos solúveis totais, determinados em diversas regiões da polpa, foram submetidos à análise da variância, sendo as médias de cada data de avaliação comparadas entre si pelo teste de Duncan, em nível de 5\% de probabilidade de erro.

\section{RESULTADOS E DISCUSSÃO}

Os frutos do meloeiro apresentaram uma maior evolução no diâmetro longitudinal e transversal até os 22 dias após a antese (DAA) (crescimento acelerado) (Figura
1A). Posteriormente, os frutos diminuíram seu crescimento, apresentando uma estabilização até sua maturação. Esse padrão de crescimento seguiu uma curva do tipo sigmoidal simples (Figura 1A). A fase de crescimento acelerado corresponde ao estádio no qual há elevada divisão celular, seguida de fase na qual predomina a expansão celular até o amadurecimento, sendo acompanhada pelo acúmulo de açúcares e outros compostos (GILLASPY et al., 1993). Em melões ‘Piel de Sapo' e 'Rochet', Villanueva et al. (2000) observaram um crescimento significativo em ambas cultivares até a primeira metade do ciclo, permanecendo praticamente constante a partir dos 27 DAA.

Os frutos apresentaram baixa produção de etileno até os 31 DAA, quando houve um aumento drástico na produção desse fito-hormônio (Figura 1B). O pico de produção de etileno ocorreu aos $37 \mathrm{DAA}$, com valor de 44 $\pm 4,6 \mathrm{~mL} \mathrm{~kg}^{-1} \mathrm{~h}^{-1}$, coincidindo com o início do amadurecimento dos frutos e seu desprendimento das plantas. Segundo Seymour \& McGlasson (1993), melões reticulados produzem quantidades apreciáveis de etileno na colheita ou muito próximo a ela.

A respiração dos frutos aumentou a partir dos 34 DAA, com valor máximo em torno de $57,1 \pm 2,6 \mathrm{~mL}$ de $\mathrm{CO}_{2} \mathrm{~kg}^{-1} \mathrm{~h}^{-1}$ aos 37 DAA (Figura 1B). Esse comportamento é característico de frutos climatéricos. Arespiração de melões 'Honey Dew' possui correlação direta com a produção de etileno, devido às mudanças bioquímicas proporcionadas por esse fito-hormônio (BOWER et al., 2002; PRATT et al., 1977).

Os frutos apresentaram perda acentuada da firmeza da polpa, especialmente após 31 DAA (Figura 1D). Observou-se um decréscimo na firmeza da polpa de apenas $35 \%$ dos 25 aos 34 DAA. A partir desse período, até os 37 DAA, houve um decréscimo de $62 \%$, provavelmente influenciado pelo aumento da concentração de etileno endógeno. A redução da firmeza da polpa, em melões, é decorrente da degradação da parede celular (ROSE et al., 1998). Esses mesmos autores observaram que a redução da firmeza da polpa em melões é precedida por um incremento na síntese de etileno e um aumento na despolimerização e solubilização das substâncias pécticas, devido ao aumento da atividade enzimática, especialmente de poligalacturonases.

A acidez total titulável decresceu durante o período avaliado, especialmente entre os 31 e 34 DAA (Figura 1E). Possivelmente, esse comportamento ocorreu em reposta ao aumento na síntese de etileno, diminuindo principalmente o teor de ácido cítrico, que é o principal ácido orgânico em melões (SEYMOUR \& McGLASSON, 1993). O metabolismo de ácidos orgânicos, em melões 'Védrantais', é um processo dependente de etileno (SILVA et al., 2004). 

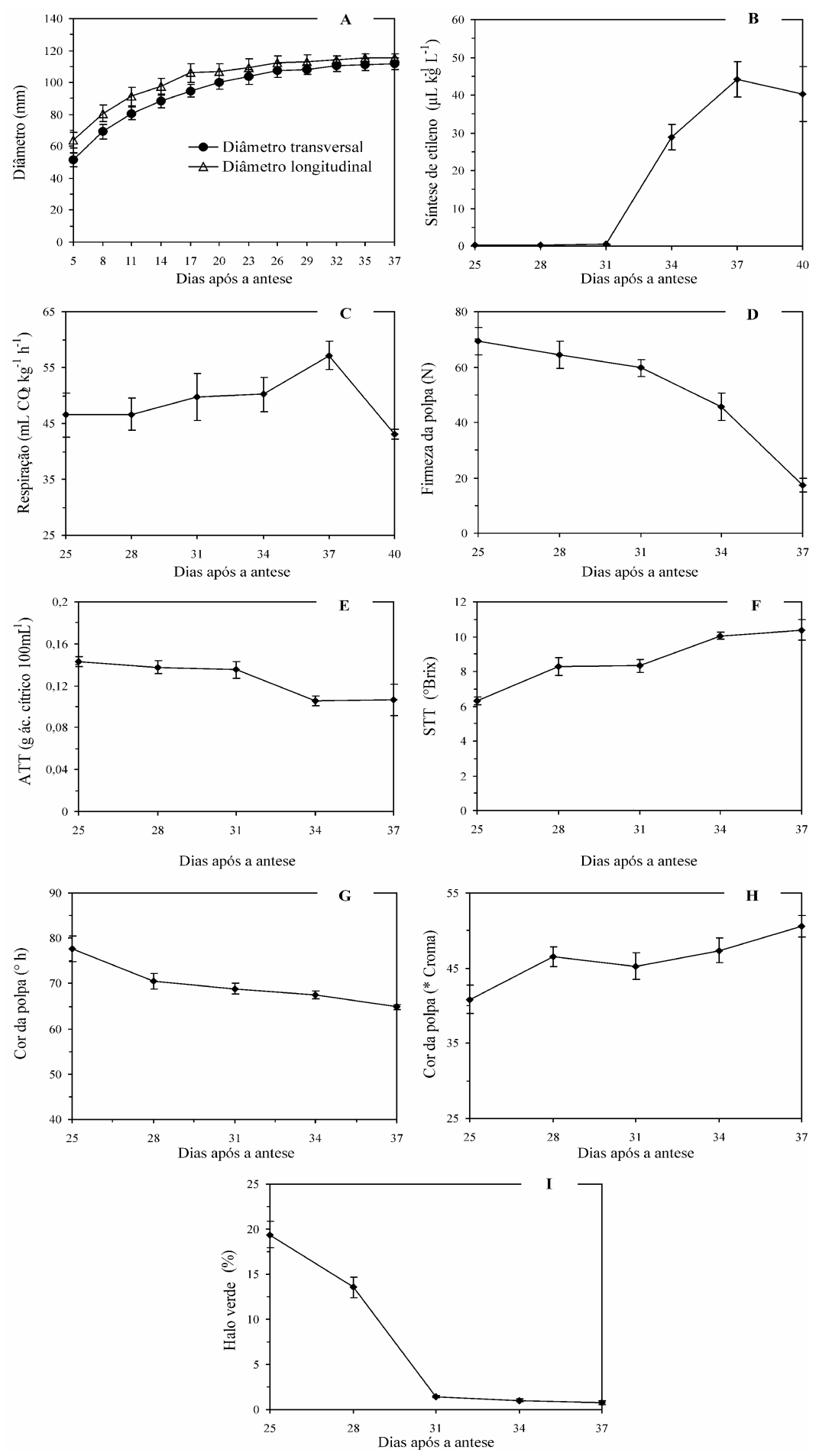

Figura 1 - Diâmetro transversal e longitudinal (A), síntese de etileno (B), respiração (C), firmeza da polpa (D), sólidos solúveis totais $(\mathrm{SST})(\mathrm{E})$, acidez total titulável (ATT) $(\mathrm{F})$, cor da polpa em ângulo hue $\left(\mathrm{h}^{\circ}\right)(\mathrm{G})$ e croma $(\mathrm{H})$ e porcentagem de halo verde (I), em melões (Cucumis melo var. cantalupensis Naud.), híbrido Torreon. Estão representados os valores médios, sendo as barras verticais correspondentes aos desvios-padrões (n=10). Santa Maria, RS. 2004. 
Os teores de sólidos solúveis totais (SST), extraídos do suco obtido de toda a polpa da fruta, aumentaram durante o crescimento e desenvolvimento dos frutos, apresentando uma variação de $4,0^{\circ}$ Brix dos 25 aos 37 DAA (Figura 1F). Segundo Hubbard et al. (1989), a maior parte do açúcar encontrado no melão é a sacarose, que se acumula durante os estádios finais de desenvolvimento dos frutos, aproximadamente nas duas semanas que antecedem a colheita. Os teores de sólidos solúveis totais observados nesse trabalho, aos 37 DAA, foram de $10,4^{\circ}$ Brix, sendo que, para os padrões estabelecidos pela Frupex (1994), frutos com teores entre 9 e $12^{\circ}$ Brix são considerados comercializáveis. Em parte, os baixos valores encontrados, podem ter sido influenciados pela diminuição na disponibilidade de radiação solar, em função da aproximação do solstício de inverno, principalmente durante o período de maturação dos frutos (Figura 2). Os valores máximos de temperatura, durante o ciclo de cultivo, situaram-se entre 27 e $30^{\circ} \mathrm{C}$ (Figura 2).

Ocorreu uma variação dos teores de SST nos diversos pontos da polpa dos frutos (Tabela 1). Aos 37 DAA, o maior acúmulo ocorreu da porção mediana dos frutos em direção à extremidade apical e da região próxima à cavidade central em direção à casca, exceto na extremidade apical, onde foi maior próximo à casca. Os valores, nessa avaliação, oscilaram entre 9,2 e $12,8^{\circ}$ Brix, demonstrando um diferente padrão de acumulação dos SST dentro dos frutos. Silva et al. (2003), verificaram que, em melões, os maiores valores de sólidos solúveis totais ocorrem na porção mediana e apical, respectivamente. Em função disso, deve-se ter cuidado na escolha da região a ser amostrada para a análise de sólidos solúveis totais, podendo, em alguns casos, ser necessário extrair o suco de toda a polpa para a posterior análise.

A cor da polpa, expresso em ângulo de cor $\left({ }^{\circ} \mathrm{h}\right)$, decresceu lentamente durante os 28 a 37 DAA, tornando-se mais alaranjada (Figura 1G). Por outro lado, os valores de croma $\left({ }^{*} \mathrm{C}\right)$ aumentaram nesse intervalo (Figura $1 \mathrm{H}$ ), indicando que a cor da polpa tornou-se mais pura (McGUIRE, 1992). A alteração da cor da polpa, em melões, deve-se à degradação de clorofilas e ao aumento na síntese de carotenóides (McGLASSON \& SEYMOUR, 1993), sendo um processo independente de etileno (SILVA et al., 2004). A proporção do halo verde da polpa, que representa uma região com elevada concentração de clorofila situada abaixo da casca e que se estende para a polpa, diminuiu drasticamente até os 31 DAA (Figura 1I). Esse resultado pode indicar que esse processo é independente do etileno, pois ocorreu antes do aumento na síntese desse fito-hormônio, ou que pode ser desencadeado por concentrações de etileno extremamente baixas (Figura 1B).

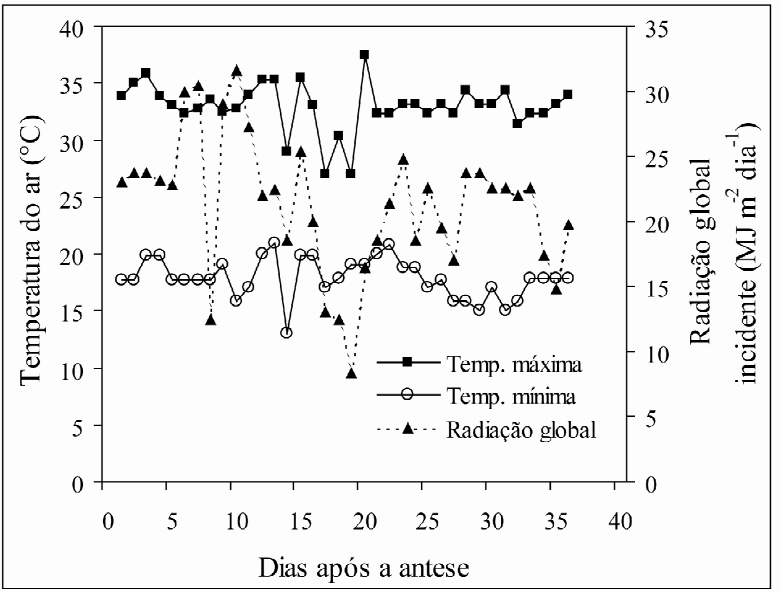

Figura 2 - Variação da temperatura mínima ( $\mathrm{T}^{\circ}$ mínima $)$ e máxima ( $\mathrm{T}^{\circ}$ máxima) do ar e da radiação solar global durante o crescimento e a maturação de melões (Cucumis melo var. cantalupensis Naud.), híbrido Torreon. Santa Maria, RS. 2004.

Os frutos amadureceram entre os 35 e 39 DAA, período em que se desprenderam do pedúnculo das plantas. Esses valores são semelhantes aos obtidos por Pardossi et al. (2000), para melões reticulados 'Calipso', os quais amadurecem entre 30-35 DAA, quando cultivados no verão, e após 40 DAA, quando cultivados na primavera. Esses mesmos autores atribuíram esses resultados às diferentes temperaturas diárias ocorridas durante essas estações, que possibilitaram um menor acúmulo de graus dia na primavera, prolongando o ciclo. $\mathrm{O}$ amadurecimento foi precedido pela formação da zona de abscisão na inserção do pedúnculo, entre três e cinco dias antes do desprendimento dos frutos (dados não apresentados), concordando com a constatação de que esse processo é dependente de etileno (AYUB et al., 1996). Todavia, além do etileno, outros fatores, como a aceleração da produção de ácido abscísico ou diferenças anatômicas na região peduncular de frutos de diferentes genótipos, podem estar envolvidos nesse processo (KENDALL \& NG, 1988). O início da formação da zona de abscisão só ocorreu após o rendilhamento ter coberto todo o fruto e ter atingido a extremidade peduncular. Próximo ao desprendimento dos frutos (de um a dois dias), verificou-se a formação de aroma intenso nos frutos (dados não apresentados). Esse período compreende o aumento na produção de etileno, sendo que a regulação das enzimas álcool-desidrogenases $(\mathrm{Cm}$ $A D H 1-2)$, as quais participam na rota de biossíntese de compostos aromáticos em melões, é dependente da ação desse fito-hormônio (MANRÍQUEZ et al., 2006). 
Tabela 1 - Variação dos teores de sólidos solúveis totais $\left({ }^{\circ}\right.$ Brix $)$, determinados em diferentes locais da polpa dos frutos durante a maturação de melões (Cucumis melo var. cantalupensis Naud.), híbrido Torreon. Santa Maria, RS. 2004.

\begin{tabular}{|c|c|c|c|c|c|c|}
\hline \multicolumn{2}{|c|}{ Porções de extração do suco } & \multicolumn{5}{|c|}{ Sólidos solúveis totais $\left({ }^{\circ}\right.$ Brix $)$} \\
\hline \multirow{2}{*}{ Região } & \multirow{2}{*}{ Próximo } & \multicolumn{5}{|c|}{ Dias após a antese } \\
\hline & & 25 & 28 & 31 & 34 & 37 \\
\hline Basal ou peduncular & Casca & $6,4 a^{*}$ & $6,4 \mathrm{~d}$ & $8,2 \mathrm{a}$ & $9,1 \mathrm{~cd}$ & $9,2 \mathrm{~d}$ \\
\hline Basal ou peduncular & Cavidade central & $6,7 \mathrm{a}$ & 8,0 abc & $8,7 \mathrm{a}$ & $11,0 \mathrm{~b}$ & $11,0 \mathrm{bc}$ \\
\hline Mediana & Casca & $6,4 \mathrm{a}$ & $8,5 \mathrm{a}$ & $7,9 \mathrm{a}$ & $9,1 \mathrm{~cd}$ & $9,7 \mathrm{~cd}$ \\
\hline Mediana & Cavidade central & $6,5 \mathrm{a}$ & 8,9 a & $8,7 \mathrm{a}$ & $12,1 \mathrm{a}$ & $12,8 \mathrm{a}$ \\
\hline Apical & Casca & $6,0 \mathrm{a}$ & $7,1 \mathrm{~cd}$ & $7,8 \mathrm{a}$ & $8,9 \mathrm{~d}$ & $11,2 \mathrm{bc}$ \\
\hline Apical & Cavidade central & $6,0 \mathrm{a}$ & $7,4 \mathrm{bc}$ & $8,2 \mathrm{a}$ & $9,8 \mathrm{~cd}$ & $11,6 \mathrm{ab}$ \\
\hline Toda a polpa & & $6,3 \mathrm{a}$ & $8,3 \mathrm{ab}$ & $8,3 \mathrm{a}$ & $10,0 \mathrm{bc}$ & $10,6 \mathrm{bc}$ \\
\hline Coeficiente de variação (\%) & & 6,00 & 6,95 & 10,63 & 5,64 & 7,76 \\
\hline
\end{tabular}

*Médias seguidas de mesma letra, na vertical, não diferem entre si pelo teste de Duncan, em nível de 5\% de probabilidade de erro.

\section{CONCLUSÕES}

A plena maturação de melões (Cucumis melo var. cantalupensis Naud.), híbrido Torreon, cultivado em sistema hidropônico (NFT) nas condições de verãooutono, na região mesoclimática de Santa Maria, RS, ocorre entre os 32-34 DAA. A maturação desses frutos é caracterizada pela produção de etileno, aumento na respiração, diminuição acentuada na firmeza da polpa e na acidez total titulável, sendo os teores de SST adequados atingidos aos 34 DAA.

\section{REFERÊNCIAS BIBLIOGRÁFICAS}

AYUB, R.; GUIS, M.; BEM-AMOR, M.; GILLOT, L.; ROUSTAN, J. P.; LATCHÉ, A.; BOUZAYEN, M.; PECH, J. C. Expression of ACC oxidase antisense gene inhibits ripening of cantaloupe melon fruits. Nature Biotechnology, London, v. 14, p. 862-866, 1996.

BOWER, J.; HOLFORD, P.; LATCHÉ, A.; PECH, J. C. Culture conditions and detachment of the fruit influence the effect of ethylene on the climacteric respiration of melon. Postharvest Biology and Technology, Amsterdam, v. 26, p. 135-146, 2002.

CARON, B. O.; HELDWEIN, A. B. Consumo d'água e coeficiente de cultura para o meloeiro cultivado em estufa plástica na primavera. Revista Brasileira de Agrometeorologia, Santa Maria, v. 8, n. 1, p. 19-25, 2000 .
CASTEllane, P. D.; ARAUJO, J. C. Cultivo sem solo: hidroponia. Jaboticabal: FUNEP, 1995. 43 p.

FRUPEX. Melão para a exportação: procedimentos de colheita e pós-colheita. Brasília, DF: Embrapa-SPI, 1994. $37 \mathrm{p}$.

GILLASPY, G.; BEN-DAVID, H.; GRUISSEM, W. Fruits: a developmental perspective. Plant Cell, Rockville, v. 5, p. 1439-1451, 1993.

HUBBARD, N. L.; HUBER, S. C.; PHARR, D. M. Sucrose phosphate synthase and acid invertase as determinants of sucrose concentration in developing muskmelon (Cucumis melo L.) fruits. Plant Physiology, Rockville, v. 91, p. 1527-1534, 1989.

KENDALL, S. A.; NG, T. J. Genetic variation of ethylene production in harvested muskmelon fruits. Hortscience, Alexandria, v. 23, p. 759-761, 1988.

MANRÍQUEZ, D.; EL-SHARKAWY, I.; FLORES, F. B.; ELYAHYAOUI; REGAD, F.; BOUZAYEN, M.; LATCHÉ, A.; $\mathrm{PECH}, \mathrm{J}$. C. Two highly divergent alcohol dehydrogenases of melon exhibit fruit ripening-specific expression and distinct biochemical characteristics. Plant Molecular Biology, [S.1.], v. 61, p. 675-685, 2006.

McGUIRE, R. G. Reporting of objective color measurements. HortScience, Alexandria, v. 27, n. 12, p. 1254-1255, 1992. 
PARDOSSI, A.; GIACOMET, P.; MALORGIO, F.; ALBINI, F. M.; MURELLI, C.; SERRA, G.; VERNIERI, P.; TOGNONI, $\mathrm{F}$. The influence of growing season on fruit yield and quality of the greenhouse melon (Cucumis melo L.) grown in nutrient film technique in a Mediterranean climate. Journal of Horticultural Science and Biotechnology, Ashford, v. 75, n. 4, p. 488-493, 2000.

PRATT, H. K.; GOESCHL, J. D.; MARTIN. F. W. Fruit growth and development, ripening and role of ethylene in the 'Honey Dew' muskmelon. Journal of the American Society for Horticultural Science, Alexandria, v. 102, p. 203-210, 1977.

ROSE, J. K. C.; HADFIELD, K. A.; LABAVITCH, J. M.; BENNETT, A. B. Temporal sequence of cell wall disassembly in rapidly ripening melon fruit. Plant Physiology, Rockville, v. 117, p. 345-361, 1998.

SEYMOUR, G.; McGLASSON. Melons. In: SEYMOUR, G.;
TAYLOR, J.; TUCKER, G. Biochemistry of fruit ripening. London: Chapman \& Hall, 1993. 454 p.

SILVA, J. A.; COSTA, T. S.; LUCCHETA, L.; MARINI, L. J.; ZANUZO, M. R.; NORA, L.; NORA, F. R.; TWYMAN, R. M.; ROMBALDI, C. V. Characterization of ripening behavior in transgenic melons expressing an antisense 1aminocyclopropane-1-carboxylate (ACC) oxidase gene from apple. Postharvest Biology and Technology, Amsterdam, v. 32, p. 263-268, 2004.

SILVA, P. S. L.; MENEZES, J. B.; OLIVEIRA, O. F.; SILVA, P. I. B. Distribuição do teor de sólidos solúveis totais no melão. Horticultura Brasileira, Brasília, v. 21, n. 1, p. 3133, 2003.

VILLANUEVA, M. J.; TENORIO, M. D.; ESTEBAN, M. A.; MENDOZA, M. C. Compositional changes during ripening of two cultivars of muskmelon fruits. Food Chemistry, Amsterdam, v. 87, p. 179-185, 2000. 